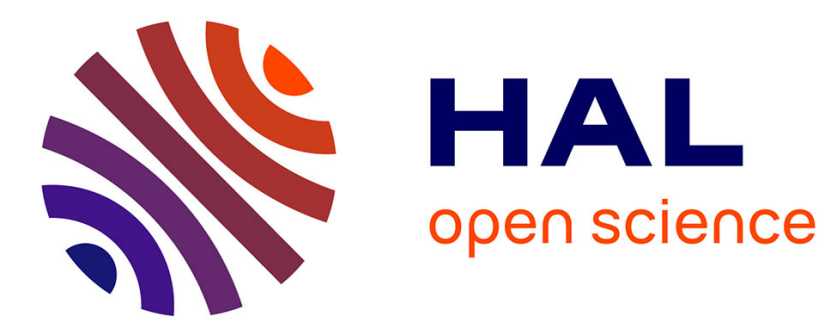

\title{
Four remarks on the growth of channel networks
}

\author{
Ap Petroff, O Devauchelle, A Kudrolli, Dh Rothman
}

\section{To cite this version:}

Ap Petroff, O Devauchelle, A Kudrolli, Dh Rothman. Four remarks on the growth of channel networks. Comptes Rendus Géoscience, 2012, 344 (1), pp.33-40. 10.1016/j.crte.2011.12.004 . hal-01500388

\section{HAL Id: hal-01500388 \\ https://hal.science/hal-01500388}

Submitted on 12 Apr 2017

HAL is a multi-disciplinary open access archive for the deposit and dissemination of scientific research documents, whether they are published or not. The documents may come from teaching and research institutions in France or abroad, or from public or private research centers.
L'archive ouverte pluridisciplinaire HAL, est destinée au dépôt et à la diffusion de documents scientifiques de niveau recherche, publiés ou non, émanant des établissements d'enseignement et de recherche français ou étrangers, des laboratoires publics ou privés. 


\title{
Four Remarks on the Growth of Channel Networks Quatre remarques sur la croissance d'un réseau de drainage
}

\author{
Alexander P. Petroff, Olivier Devauchelle ${ }^{*}$, Arshad Kudrolli ; and Daniel H. Rothman*
}

26 décembre 2011

\begin{abstract}
Résumé
Les ravines creusées par le suintement d'un aquifère forment parfois un réseau ramifié, dont la dynamique peut être comprise simplement. Elles constituent ainsi un système naturel propice à l'étude de la croissance des réseaux. Nous présentons ici quatre facettes de cette dynamique simple, qui permettent d'établir une théorie quantitative de la formation d'un réseau de drainage naturel à l'échelle du kilomètre. En quatre sections distinctes, nous nous efforçons de relier le débit d'eau qui s'écoule dans une rivière à la géométrie du réseau, de comprendre la forme du profil d'élévation de ces rivières, et l'influence de l'ensoleillement de la topographie sur l'érosion du plateau dans lequel croissent les ravines. Dans chaque cas, nous proposons une comparaison quantitative avec des mesures in situ.
\end{abstract}

\begin{abstract}
Networks fed by subsurface flow are a natural, but dynamically simple, system in which to consider general problems of network growth. Here we present four examples in which this dynamic simplicity can be used to develop a quantitative understanding of a natural kilometer-scale network of streams. In these four sections, we investigate the relation between the position of a spring in the network and the groundwater flux into it, the flow of water through streams and the stream shape, and the influence of solar radiation on the rate of sediment transport around the streams. In each case a quantitative comparison is made between theory and observation.
\end{abstract}

Keywords : Geomorphology, hydrology, rivers network

Mots clés : Géomorphologie, hydrologie, réseaux de rivières

\section{Introduction}

When rain falls on a sandy landscape, it flows into the aquifer, eventually re-emerging

*. Lorenz Center and Department of Earth, Atmospheric and Planetary Sciences, Massachusetts Institute of Technology, Cambridge, MA, USA

$\dagger$. Institut de physique du globe de Paris - Sorbonne Paris Cité, Université Paris Diderot, UMR CNRS 7154

‡. Department of Physics, Clark University, Worcester, MA, USA into streams. As groundwater flow accumulates in streams, sediment is removed and the landscape is eroded. This interplay between subsurface flow, erosion of the surrounding landscape, and the removal of sediment through streams causes existing stream heads to grow forward and new streams to form. In this way, groundwater-fed streams grow into ramified networks [1].

Proposed examples of these so-called seepage 
channels can be found on both Earth [2-4] and Mars [5]. Of these systems, a seepage network on the Florida Panhandle stands out as a superb example of the type. A topographic map of the network is shown in figure 1 [6].

This kilometer-scale network is incised into a $65 \mathrm{~m}$ deep bed of sand overlying an impermeable layer of muddy marine carbonates and sands [4]. The sand layer corresponds to the ancient delta of the Appalachicola river, which was deposited from late Pliocene to Pleistocene $[7,8]$. The incision of ravines into the sand plateau probably started about $1 \mathrm{My}$ ago [6]. This origin explains the remarkable homogeneity of the lithology, only perturbed by localized clay lenses. The vertical localization of the streams seems not to depend on stratigraphy [4]. Groundwater flows through the sand above the impermeable substratum, into the network of streams, and drains into a nearby river $[4,6]$.

The dynamics shaping groundwater-fed networks are simpler than the more common type of drainage networks that are fed by overland flow. In particular, the flow of the groundwater into streams is determined by the shape of the water table, which is a solution to a Poisson equation [9]. Because the growth of streams fed by groundwater is an example of network growth in a Poisson field, the analysis of landscapes shaped by this process benefits from a substantial literature on interface growth in a harmonic fields [10-12]. Past work [13] has shown that the flow of groundwater into the Florida network is accurately described by the Poisson equation.

Here we use the specific example of the Florida seepage network to explore the general connection between the geometry and growth of drainage networks. This exploration takes the form of four thematically related, but independent, exercises in which the dynamic simplicity of seepage erosion is exploited to develop a quantitative understanding of field observations. The focus of this collection is the realization that groundwater flow and land-

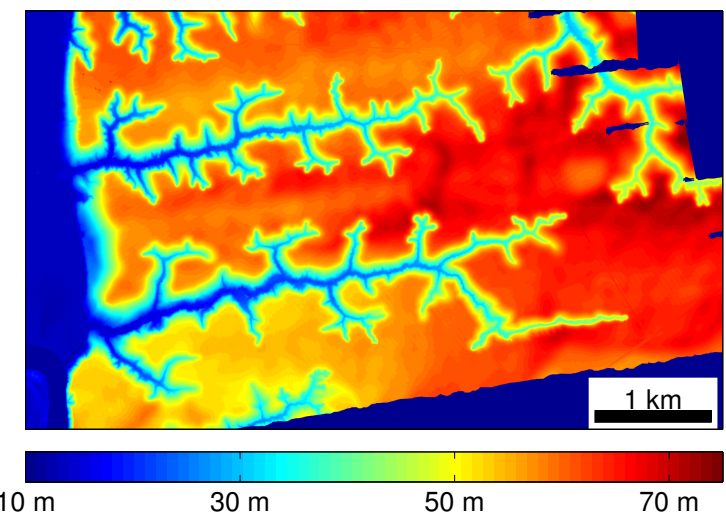

Figure 1 - A kilometer-scale network of seepage valleys from the Florida Panhandle. These valleys are incised tens of meters into unconsolidated sand. Groundwater flows from the sand bed, through the channels, and through the bluff to the west of the network. Color indicates elevation above sea-level.

Figure 1 - Réseau kilométrique de ravines d'incision dans le Nord de la Floride. Ces vallées ont incisé le sable non consolidé sur une dizaine de mètres de pronfondeur. L'eau souterraine alimente le réseau de rivières au travers de leur lit sableux, et s'écoule vers l'Ouest jusqu'à la limite du plateau. La couleur indique l'élévation au-dessus du niveau de la mer. 
scape erosion are coupled to one another by the stream network, and the empirical validation that, close to equilibrium, this coupling takes a simple form. Related oddities and novelties are also briefly discussed.

\section{Estimating groundwater flow from network geometry}

We first investigate the relationship between a heuristic geometrical model for groundwater flow and the Dupuit approximation [9], which is based on well-defined physical assumptions. We begin by considering a spring, the head of a stream where groundwater first reemerges to the surface. In particular, we compare two models that relate the position of a spring in the network to the flow of water into it. In the field site we consider here, the ground surface is permeable enough to instantaneously absorb most of the rainfall. As a consequence, the water is transported to the stream almost exclusively as groundwater $[4,6]$.

Our first model is the continuum model alluded to in the introduction. According to the Dupuit approximation of Darcy's Law [9], the water flux $\mathbf{q}$ is related to the height $h$ of the water table above the impermeable layer as

$$
\mathbf{q}=-K h \nabla h,
$$

where $K$ is the hydraulic conductivity. At steady-state, conservation of mass requires a balance of the precipitation rate $P$ with the divergence of the flux. Thus, the height of the water table is a solution of the Poisson equation

$$
\frac{K}{2} \nabla^{2} h^{2}=-P .
$$

Because the change in elevation along the Florida network is small (the median slope $S \sim 10^{-2}$ ), we approximate the height of the streams above the impermeable layer as constant. Because this equation is linear in the variable $\phi=K h^{2} / 2 P$, this boundary-value problem around the streams of the Florida network can be solved using the finite element method $[13,14]$.

The second model of subsurface flow is a heuristic geometrical model [6]. According to this approximation, all groundwater flows towards the nearest point on the stream network. Thus, to find the flux of water into a section of the network, one first identifies the area $a$ around the streams that is nearer to the selected section than to any other point on the streams. This drainage area is not related to the topographic drainage area, which is commonly used to model surface runoff. From conservation of mass, the discharge of groundwater into this section is $Q_{g}=P a$.

Using these two models, we proceed to compare the estimated groundwater flux into 82 springs from the Florida network. To do so, it is useful to define the Poisson flux $q_{p}=\|\nabla \phi\|$. Physically, $q_{p}$ is the area draining into a section of stream per unit length. By analogy, the geometric flux into a section of network of length $\delta s$ and drainage area $a$ is $q_{g}=a / \delta s$. Because the area-driven model allows a finite area to drain into a point, this definition requires a finite value of $\delta s$; we take $\delta s=11 \mathrm{~m}$. As shown in figure (2), there is a power law relationship $\left(R^{2}=0.94, p<10^{-35}\right)$ between these quantities, $q_{g}=B q_{g}^{\alpha}$. The scaling exponent $\alpha=0.69 \pm 0.06$. The proportionality constant, $B=4.0 \pm 1.6 \mathrm{~m}^{1-\alpha}$, likely depends on the choice of $\delta s$.

Although there is no general quantitative relationship between these measures, there is a formal relationship. Let us imagine that each rain drop falls randomly, with a uniform distribution over the domain, and then undergoes a random walk until it reaches a boundary. The probability distribution of the random walkers' positions satisfies the Poisson equation, which can be interpreted as a diffusion equation with a uniform source term [15]. As a consequence of its random walk through the domain, this imaginary rain drop has a continuous and non- 


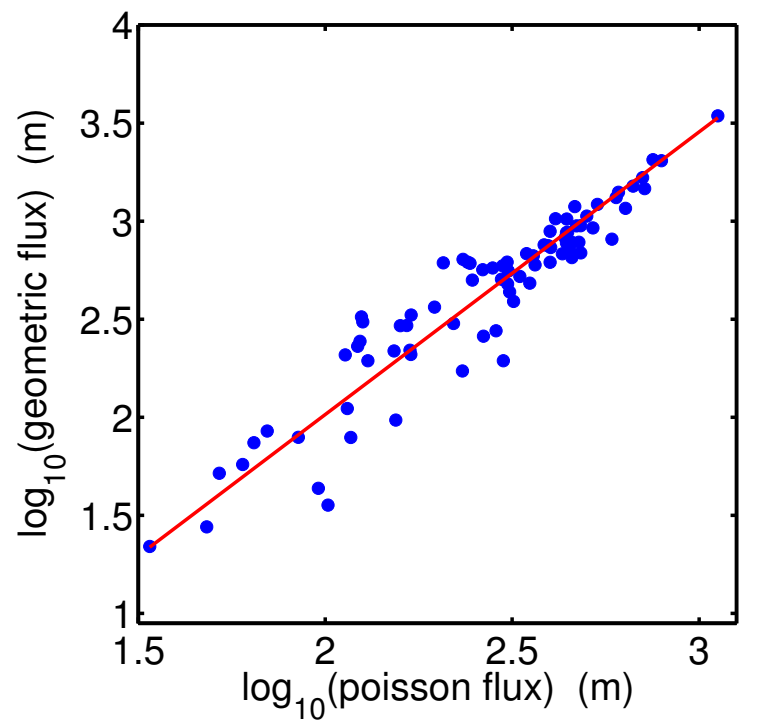

Figure 2 - Comparison of the flow into 82 springs from the Florida network as estimated from Darcy's law ("Poisson flux") and a heuristic model ("geometric flux" [6]). The red line shows the best fitting power-law.

Figure 2 - Comparaison, pour 82 rivières du réseau de Floride, du débit prédit par la loi de Darcy ( flux de Poisson $\gg)$ et du débit prédit par le modèle géométrique (« flux géométrique $\gg,[6]$ ). La ligne rouge correspond à l'ajustement d'une loi de puissance. vanishing probability distribution $p$ of exit locations along the boundary, with a maximum at the closest point on the boundary. The mean flux of walkers through the section of channels gives the Poisson flux. To find the geometric drainage area, one sends each random walker to the mode of $p$. Thus, the precise relationship between $q_{g}$ and $q_{p}$ depends on the geometry of the system and, consequently, the scaling exponent $\alpha$ relating these quantities is likely not universal.

We conclude that the area-driven model can be safely used as a conceptual tool with which to gain intuition. Nevertheless, the Poisson equation should be used whenever a quantitative prediction of the seepage intensity or the relative fluxes into different parts of the network is required.

\section{The three dimensional structure of the network}

Having discussed the flow of water into a stream, we now consider the response of sediment within the stream to the flowing water. Flowing water erodes the bottom of the sandy stream when the shear force exerted on a sand grain is sufficient to overcome friction. Thus, there is a threshold that the shear must exceed for any sediment to be transported. This threshold is often expressed as a function of the Shields parameter (which compares the grain weight to the flow-induced shear) in bedload transport laws $[16,17]$. Many streams, and the Florida network in particular, are thought to adjust to a state in which every grain is on the threshold of motion [18-20]. If we further approximate the stream with a straight and shallow channel formed in uniform sediment, the above constraint on the shear can be reexpressed as a relationship between the slope of the stream bed $S$ and the discharge $Q$ (units of volume/time) of water in the stream as

$$
Q S^{2}=Q_{0}
$$


where $Q_{0}$ is a constant with units of discharge the value of which depends on parameters such as the grain size. [18-20]. Thus the threshold theory provides a new interpretation to the typical relationship between slope and area [21]. Using the conservation of mass and momentum, this equation becomes equivalent to Lacey's relation, which states that the width of a stream scales like the square root of its discharge [22].

Because both the discharge of a stream and the slope affect the flow of groundwater into it, equation (3) imposes a boundary condition for the flow of groundwater into the streams, from which one can derive the profile of an isolated stream [20]. Here we show that this boundary condition is satisfied throughout the network.

To test the applicability of equation 3 , we compare the measured slope of streams to the stream discharge. Estimates of both the slope and the discharge require a three-dimensional description structure of the drainage network, which is extracted from the high-resolution topographic map of the network shown in figure 1. A depiction of part of the network is shown in figure 3 . Given the height $H_{s}$ of each point of the network, the slope is measured from the change in height along the stream. To estimate estimate $Q$, we first solve equation (2) subject to the boundary condition on the streams

$$
h=H_{s} .
$$

Because equation (2) is a non-linear function of $h$, its solution depends on the height of the streams above the impermeable mudstone layer. The elevation of the impermeable layer above sea-level is $h_{0}=0$. Figure 4 shows the height of the water table around the network taking $P=510^{-8} \mathrm{~m} / \mathrm{s}, K=1.610^{-5} \mathrm{~m} / \mathrm{s}$. The value of the precipitation rate $P$ corresponds to the yearly average rainfall in the concerned area. The value of the conductivity $K$ was adjusted independently to match the distribution of discharges measured in the field [13]. Given

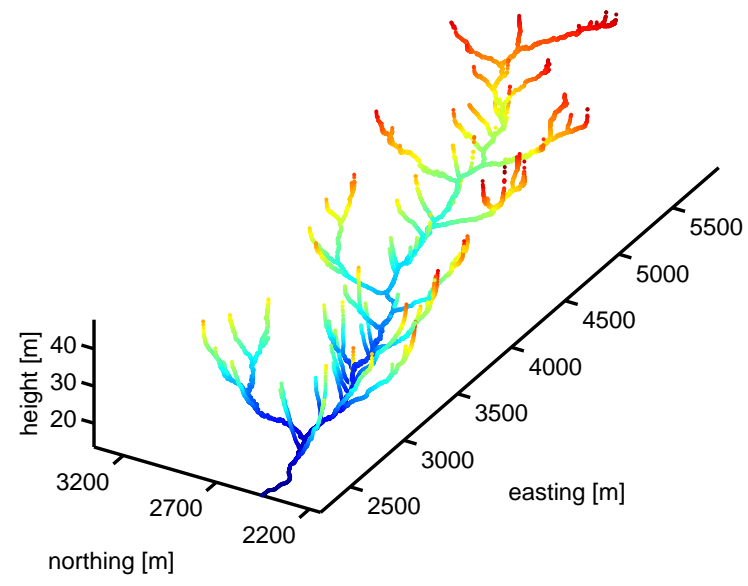

Figure 3 - The three-dimensional shape of a stream network measured from a topographic map. Color indicates elevation above sea-level. Streams curve upward sharply near springs. Further downstream, as flow accumulates the streams become flatter. This inverse relationship between slope and discharge is in quantitative agreement with equation (3).

FiguRE 3 - Représentation tri-dimensionnelle d'un réseau de rivière, établie à partir d'une carte topographique. La couleur indique l'élévation au-dessus du niveau de la mer. Les rivières s'incurvent nettement à proximité des sources. À l'aval, pour des débits plus élevés, la pente des rivières décroît. Cette relation inverse entre pente et débit est en accord quantitatif avec l'équation (3). 


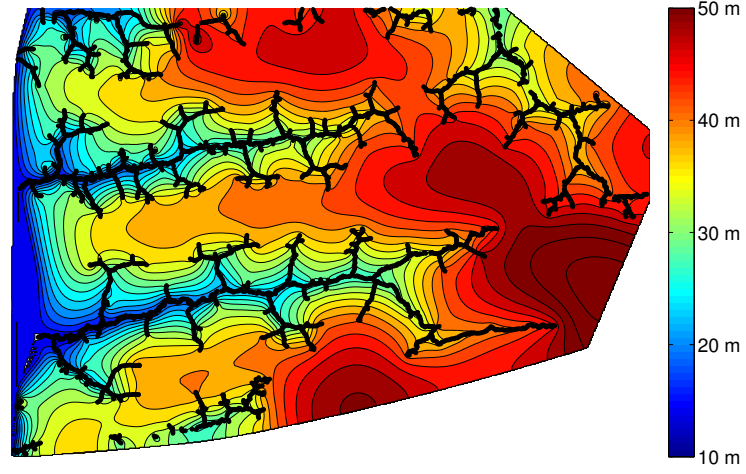

Figure 4 - The shape of the water table around the Florida network as calculated from equation (2). Black lines represent the position of streams. The water table intersects the streams at the measured height of the stream. A zero-flux boundary condition is imposed along on the polygonal boundary encompassing the channels.

FIguRE 4 - Élévation de la nappe phréatique autour du réseau de Floride, calculée à partir de l'équation (2). Les lignes noires représentent la position des rivières. La nappe intersecte les rivières à l'altitude mesurée sur la carte topographique. Une condition arbitraire de flux nul est imposée le long de la frontière polygonale englobant le réseau.

this solution, $Q$ is estimated throughout the network as

$$
Q\left(x_{0}, y_{0}\right)=-K \oint_{\mathcal{N}\left(x_{0}, y_{0}\right)} h\left[\frac{\partial h}{\partial n}\right] \mathrm{d} s,
$$

where $\mathcal{N}\left(x_{0}, y_{0}\right)$ is the network upstream of the point $\left(x_{0}, y_{0}\right), s$ is a curvilinear coordinate along the streams, $n$ is the local normal, and [.] represents the "jump", which accounts for the flow of groundwater into either side of the one-dimensional stream.

Figure 5 show the comparison between the measured slope-discharge relation (blue points) and the quadratic relation predicted by equation (3). The value of $Q_{0}$ is fit to the data and corresponds to a grain size of $d_{s}=1.7 \mathrm{~mm}$, consistent with observation. The slight disagreement between theory and observation at high and low values of discharge is likely the result of errors in the extraction of the network from the elevation map. The measurement of the discharge close to a spring is sensitive to the position and elevation of the spring in the network. The measured elevations of a substantial fraction of the springs are above the solution of the water table elevation, leading to a negative value of $Q$ very close to the spring. The measurement of very small values of the slope is also affected by error in the original topographic map. Finally, the dependence of the friction coefficient on flow depth or the downstream fining of sediments can explain the slight overestimation of the exponent by the simplest version of the threshold theory.

The approximate agreement between theory and observation leads us to conclude that the streams throughout the network are poised at the threshold of sediment motion. The solution of equation (2) subject to boundary condition (3) determines the height of the streams throughout the network [20].

\section{Response of the surrounding topography}

In the Florida network, streams are incised into a bed of unconsolidated sand. Since there is no surface runoff except for the streams themselves, the topography around them evolves as a function of slope only. The dependence of the sediment flux on slope is likely to be non-linear where the slope is close to critical. Far from the channels, however, we can represent the relaxation of the landscape by linear diffusion [23]. We have not evaluated this hypothesis, but this assumption allows us to illustrate how the effect of sunlight on diffusion can be quantified. 


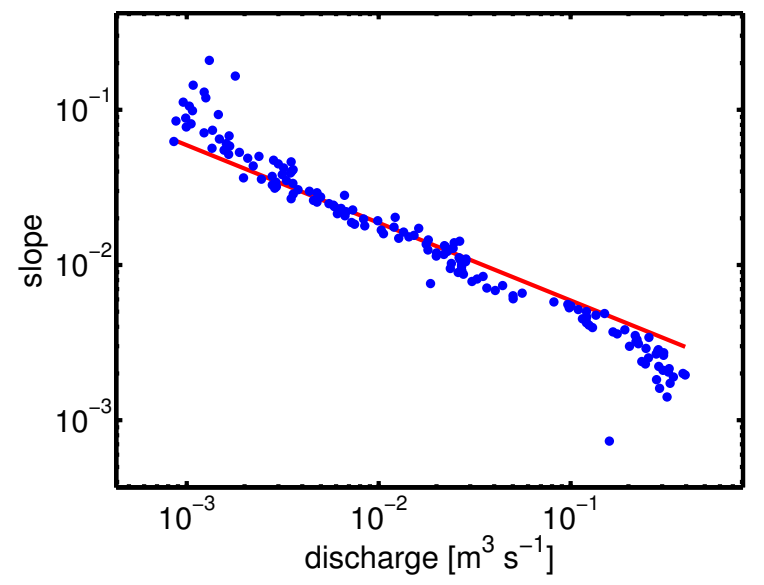

Figure 5 - Comparison of the stream discharge to the slope. Discharge is estimated from the solution of equation (2) shown in figure 4 . Slope is measured form the topographic map shown in figure 1 . The red line shows equation (3) assuming a grain size of $1.7 \mathrm{~mm}$. Each blue point represents the average of 50 points in the network with similar discharges.

Figure 5 - Débit des rivières tracé en fonction de la pente locale. Le débit est estimé à partir de la résolution de l'équation (2) (figure 4). La pente est mesurée à partir de la carte topographique (figure 1). La ligne rouge représente l'équation (3) pour une taille de grain de 1,7 $\mathrm{mm}$. Chaque point bleu représente la moyenne de 50 points de débit comparable.
According to this hypothesis, the sediment flux $\mathbf{j}$ is related to the height of the topography $H$ as

$$
\mathbf{j}=-D \nabla H,
$$

where $D$ is the diffusion coefficient. From conservation of mass,

$$
\frac{\partial H}{\partial t}=D \nabla^{2} H
$$

In general, $D$ is determined by processes including rainfall, animal activity and vegetation. In this section, we consider variations in the diffusion coefficient [24-27].

As shown in figure 6 , the valleys cut by the drainage network are asymmetric; the southern valley wall is steeper than the northern wall. This asymmetry can be interpreted in two ways. Either there is a substantial North-South variation in the rate the landscape is diffusing or the the erosion rate is symmetric but the value of $D$ is different. Because this network is in the Northern Hemisphere, the average position of the sun is to the south of the channels. Consequently, the southern walls of the valley are more shaded than the northern walls. Past studies have shown that there is a difference in vegetation between the northern and southern sides of the valley [28].

We characterize the influence of the sun with the projection of sun light onto the landscape. If $\hat{\sigma}$ is a unit vector pointing towards the sun and $\hat{N}(x, y)$ is the unit vector that is normal to the land scape at the point $(x, y)$, the dimensionless light intensity is

$$
I(x, y)=\hat{N}(x, y) \cdot \hat{\sigma} .
$$

It is straightforward to measure $\hat{N}$ from the topographic map shown in figure 1. Given the latitude and longitude of the Florida network, the annual average solar zenith and azimuthal angles are $26.6^{\circ}$ and $180^{\circ}$ respectively [29]. Combining these values with equation (8) provides an estimate of $I$ at each point in the field site. 
We hypothesize that differences in average light intensity give rise to differences in $D$, resulting in asymmetric valley walls. Expanding $D$ to first order in $I$ gives

$$
D \approx D_{0} I_{0}\left(1+D_{1} I_{1}\right)
$$

where $D_{0}$ is the mean diffusion coefficient, $I_{0}$ is the mean light intensity, $I_{1}=\left(I-I_{0}\right) / I_{0}$ is the fluctuation in the light intensity, and $D_{1}$ is the correction due to light.

Here we estimate $D_{1}$ from the shape of the topography assuming that there is no NorthSouth asymmetry in the erosion rate. It is useful to express $j=\|\mathbf{j}\|$ and $I_{1}$ in terms of the orientation $\omega$. Here, $\omega$ is defined as

$$
\cos (\omega)=\frac{\nabla H}{s} \cdot \hat{x}
$$

where $s=\|\nabla H\|$ is the topographic slope and $\hat{x}$ is a unit vector pointing eastward. The variation in $s$ and $I_{1}$, estimated throughout the field site, with orientation is shown in figure 7 . The distribution of slopes with respect to orientation shows two modes. The mode with period $2 \pi$ is in phase with sun light intensity. The mode with period $\pi / 2$ is caused by favored orientation of channels in the network, visible on figure 4 . Indeed, a slope facing one of the cardinal directions is more likely to belong to a channel wall than if it were facing another direction. Now, channel walls have a much steeper slope than the rest of the topography, hence the higher average slope associated to cardinal directions on figure 7 .

If there is no net asymmetry in the erosion rate, then

$$
\int_{0}^{2 \pi} j(\omega) \sin (\omega) \mathrm{d} \omega=0
$$

where the integrand can be equivalently interpreted as either the north-pointing component of $\mathbf{j}$ or in relation to the first Fourier coefficient. 


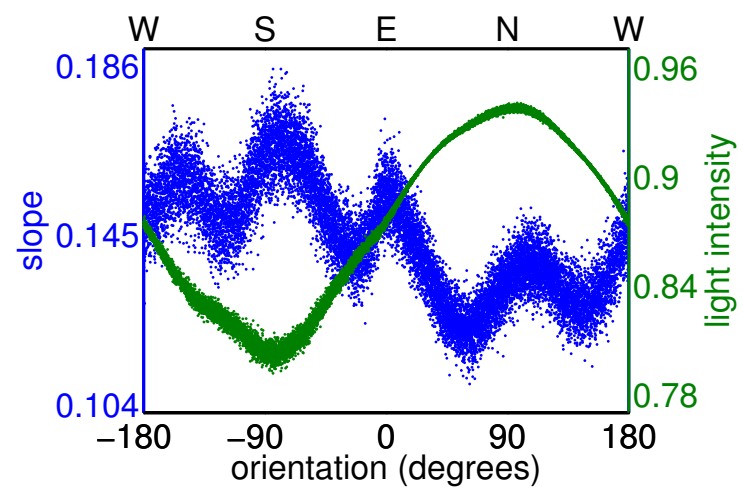

Figure 7 - Variation of slope (blue) and light intensity (green) with orientation. The slope is systematically larger on the southern sides of valleys, where the light intensity is lower. The secondary structure in the dependence of slope on orientation reflects tendency of valleys to grow in the cardinal directions, as seen in figure 1. Each point represents the average of 1000 points from the topography.

Figure 7 - Variation de la pente (en bleu) et de l'intensité lumineuse reçue (en vert) en fonction de l'orientation. La pente est systématiquement plus grande sur la partie méridionale des vallées, où l'intensité lumineuse est plus faible. Le mode secondaire dans la dépendance de la pente vis-à-vis de l'orientation reflète la tendance des vallées à se développer dans les directions cardinales, comme le montre la figure 1 . Chaque point représente la moyenne de 1000 points de la topographie.
Recognizing that $j=D_{0} I_{0}\left(1+D_{1} I_{1}\right) s$, it follows that

$$
D_{1}=-\frac{\int_{0}^{2 \pi} I_{1}(\omega) s(\omega) \sin (\omega) \mathrm{d} \omega}{\int_{0}^{2 \pi} s(\omega) \sin (\omega) \mathrm{d} \omega} .
$$

Combining the measured values of $s$ and $I$ from the Florida network with equation (12), yields $D_{1}=0.53 \pm 0.02$. Thus, the fractional variation in the diffusion coefficient needed to account for the slope asymmetry is $D_{1}\left\langle I_{1}^{2}\right\rangle^{1 / 2}=$ $0.048 \pm 0.001$

\section{Growth of a stream}

Having discussed the flow of groundwater into streams and the resulting adjustment of stream shape, and erosion of the landscape, we now turn our attention to the growth of a spring in response to the flow of groundwater. Because springs in the Florida network grow slowly, at a speed of $\sim 1 \mathrm{~mm} /$ year $[4,6]$, this section relies on experimental observations.

Seepage channels are grown in a previously described experimental apparatus [30]. In this experiment, a hydraulic head of $19.6 \mathrm{~cm}$ is used to push water through a bed of sand (grain diameter of $0.5 \mathrm{~mm}$ ), having an initial slope of $7.8^{\circ}$. As water flows out of the sand bed, it entrains sand grains, thus forming a seepage channel. The channel is initialized with a small indentation in the otherwise flat bed of sand.

We characterize the growth of a channel by the shape of an elevation contour. A map of the experiment showing the shape of an elevation contour and its position in the experiment is shown in figure 8. Given this characterization, we ask how the growth of the contour outwards depends on the flux of water into it. To this end, we compare velocity of the contour with the solution of equation (2) around the channel.

The normal velocity of the the contour is measured by comparing the shape of the contour to its shape a moment later. Given an 


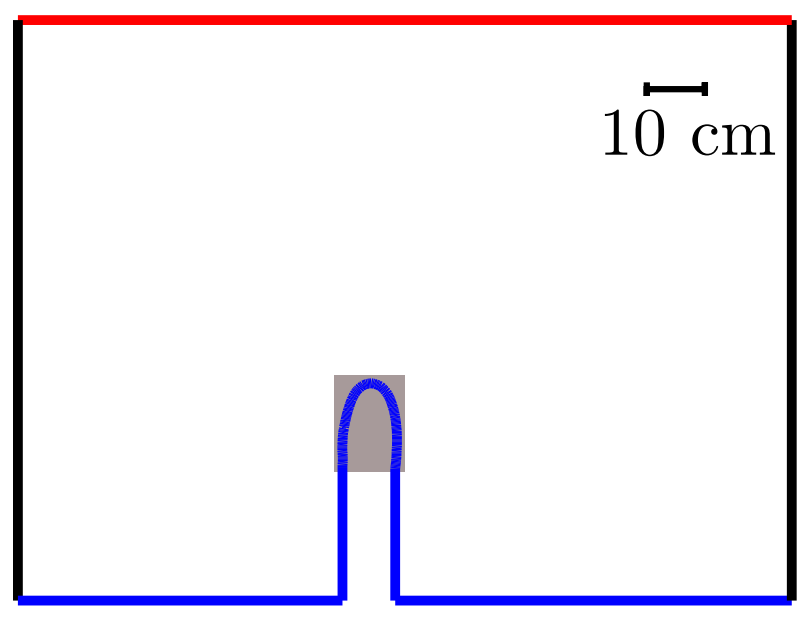

Figure 8 - Schematic of channel growth in a table-top experiment after 30 minutes of growth. The growing channel head is shown in the gray square. Water flows from from a reservoir (red line, where $\psi=1$ ). Black lines show the position of impermeable walls $(\partial \psi / \partial n=$ $0)$. Blue lines at the base show the position of a second reservoir $(\psi=0)$.

Figure 8 - Représentation schématique d'un chenal expérimental, après 30 minutes de croissance. La tête du chenal en croissance est contenue dans le carré gris. L'eau s'écoule d'un réservoir (ligne rouge, où $\psi=1$ ). Les lignes noires indiquent la position des frontières imperméables $(\partial \psi / \partial n=0)$. Les lignes bleues montrent la position d'un second réservoir $(\psi=$ $0)$.

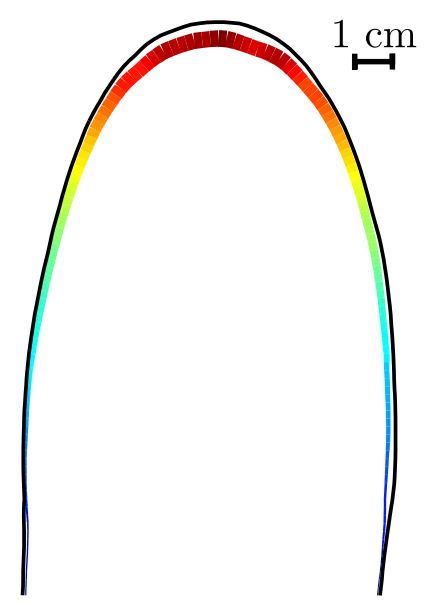

$\log _{10}$ dimensionless flux

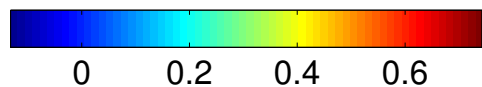

Figure 9 - Channel growth in a table top experiment. A detail (gray square in figure 8 ) of the growing channel head elevation contour. Color represents the flux of water into the boundary. The solid black line shows the position of the channel three minutes later.

Figure 9 - Croissance d'un chenal dans une expérience de laboratoire. Détail du contour d'élévation de la tête du chenal en croissance (carré gris sur la figure 8). La couleur représente l'écoulement d'eau au travers de la frontière. La ligne noire continue montre la position du chenal après trois minutes. 


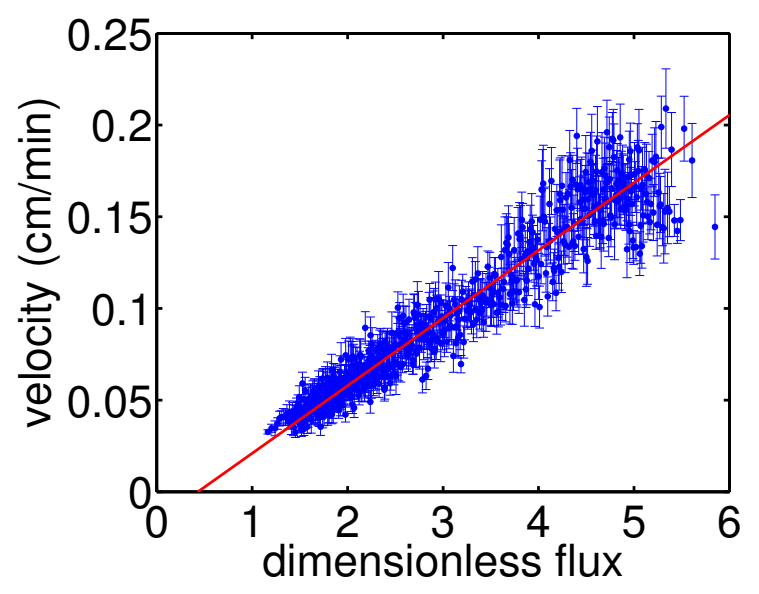

Figure 10 - Comparison of the normal velocity of the channel to the flux of water into it. The dimensionless flux is found by solving equation (13) around the measured shape of a channel. The velocity is measured from changes in the shape and position of the channel.

Figure 10 - Comparaison de la vitesse normale d'érosion du chenal au flux d'eau le traversant. Le flux sans dimension est calculé à l'aide de l'équation (13), résolue autour de la forme du chenal expérimental. La vitesse est mesurée à partir des changements de forme et de position du chenal. elevation, we determine the normal vector at each point along the associated contour. We then compare the shape of a contour to the shape of the same contour three minutes later to determine the amount that each point on the contour grew in the normal direction. Two elevation contours at three minute intervals are shown in figure 9 .

To determine the flux of water entering each part of the channel, we solve for the shape of the water table. In these experiments there is no rainfall, thus equation (2) simplifies to the Laplace equation

$$
\nabla^{2} \psi=0,
$$

where $\psi=\left(h^{2}-h_{c}^{2}\right) /\left(\Delta h^{2}-h_{c}^{2}\right)$ is the water table height above the channel (where $h=$ $h_{c}$ ) relative to the size of the hydraulic head $\Delta h=19.6 \mathrm{~cm}$. By construction, $\psi=0$ on the channel and $\psi=1$ at the back wall. Because equation (13) is linear, this boundaryvalue problem can be solved using the finite element method [14]. We solve for the shape of the water table around a growing elevation contour at one minute intervals. Figure 9 shows the dimensionless flux $q=\ell\|\nabla \psi\|$, where $\ell=90 \mathrm{~cm}$ is the length of the experiment, into different parts of the channel.

As shown in figure 10, the velocity at which the channel grows outward is linearly related to the flux of water into it. This is unexpected, as typical transport relationships relate sediment transport to shear nonlinearly. Moreover, according to the least-squares fit of the data, the intercept of this relationship is negative, meaning that a finite flux of water is required for the channel wall to grow forward. This result is superficially similar to the finite shear required to transport sediment in a stream $[16,17]$. Because the growth of the channel requires that sediment be transported through the channel, this relationship between flux and growth does not reflect a simple force balance on a sand grain. Rather, this relationship arises from the coupling between sediment transport within the 
channel and subsurface flow around the channel. It is therefore remarkable that this relationship takes a form in which the growth at a point depends only on the flux at that point. As the channel wall height remains roughly constant during the experiment, this result implies that the increase in the network volume is roughly proportional to the total delivery of water (neglecting the channel sides, where the water flux is small).

\section{Discussion}

This collection of remarks has been arranged so as to connect - the way a skipping stone connects the banks of a wide river - the flow of groundwater through the aquifer to the flow of sediment over the landscape. We began, in section 2 , by relating a heuristic model of subsurface flow to Darcy's law. In section 3, we showed that the boundary condition for the flow of groundwater is determined by the condition that sand grains in the streams are at the threshold of motion; this boundary condition determines the height of streams [20]. In section 4 we proposed a method to measure the influence of sun exposure on landscape diffusion from topographic data. Finally, in section 5, we showed that the local erosion rate of experimental seepage channels is linearly related to the water flux, beyond a threshold value.

We now pause to consider the metaphoric "wide river". The first three results represent three aspects of a single boundary value problem specified by the principal equations of these sections,

$$
\frac{K}{2} \nabla^{2} h^{2}=-P,
$$

and

$$
\frac{\partial H}{\partial t}=D \nabla^{2} H
$$

combined with the boundary condition on the streams that

$$
Q S^{2}=Q_{0}
$$

and

$$
H=h \text {. }
$$

Given the current shape of the landscape, these equations describe the evolution. It is an open question if this set of equations describes the advance of the spring. In particular, we ask if the observed relationship between channel growth and groundwater flux in section 5 represents a fourth aspect of this boundary value problem.

The answer to this question deeply influences our conceptualization of how drainage networks grow. If these equations are complete, network growth represents a balance between the accumulation of water in the streams and the erosion of the surroundings. In this case, sediment transport is simply the mechanism that maintains this balance. If these equations are not complete, the way a network grows and the surrounding landscape changes depend on the details of how sediment moves through the network. Once this question is answered, the details of this model can be adapted to suit the details of a more complex world.

\section{Acknowledgments}

We would like to thank The Nature Conservancy for access to the Apalachicola Bluffs and Ravines Preserve, and K. Flournoy, B. Kreiter, S. Herrington and D. Printiss for guidance on the Preserve. Thanks to D. M. Abrams and H. Seybold for fruitful discussions. We thank B. Smith for her experimental work. Finally, we thank the referees C. Paola, P. Davy, S. Douady and Y. Couder for their careful reviews, which helped us improve and clarify the manuscript.

This work was supported by Department of Energy grant FG02-99ER15004. O. D. was additionally supported by the French Academy of Sciences. 


\section{Références}

[1] T. Dunne. Formation and controls of channel networks. Progress in Physical Geography, 4(2) :211, 1980.

[2] C. K. Wentworth. Principles of stream erosion in Hawaii. The Journal of Geology, 36(5) :385-410, 1928.

[3] D. L. Orange, R. S. Anderson, and N. A. Breen. Regular canyon spacing in the submarine environment : the link between hydrology and geomorphology. GSA Today, 4(2) :35-39, 1994.

[4] S. A. Schumm, K. F. Boyd, C. G. Wolff, and W. J. Spitz. A ground-water sapping landscape in the Florida Panhandle. Geomorphology, 12(4) :281-297, 1995.

[5] C. G. Higgins. Drainage systems developed by sapping on Earth and Mars. Geology, 10(3) :147, 1982.

[6] D. M. Abrams, A. E. Lobkovsky, A. P. Petroff, K. M. Straub, B. McElroy, D. C. Mohrig, A. Kudrolli, and D. H. Rothman. Growth laws for channel networks incised by groundwater flow. Nature Geoscience, 28(4) :193-196, 2009.

[7] W. Schmidt. Alum bluff, liberty county, florida. Open File Report 9, Florida geological survey, 1985.

[8] F. Rupert. The geomorphology and geology of Liberty County, Florida. Number 43. Florida Geological Survey, 1991.

[9] J. Bear. Hydraulics of groundwater. McGraw-Hill New York, 1979.

[10] P. G. Saffman and G. I. Taylor. The penetration of a fluid into a porous medium or Hele-Shaw cell containing a more viscous liquid. Proceedings of the Royal Society of London. Series A, Mathematical and Physical Sciences, 245(1242) :312329, 1958.

[11] M. B. Hastings and L. S. Levitov. Laplacian growth as one-dimensional turbu- lence. Physica D : Nonlinear Phenomena, 116(1-2) :244-252, 1998.

[12] L. Carleson and N. Makarov. Laplacian path models. Journal d'Analyse Mathématique, 87(1) :103-150, 2002.

[13] A. P. Petroff, O. Devauchelle, D. M. Abrams, A. E. Lobkovsky, A. Kudrolli, and D. H. Rothman. Geometry of valley growth. Journal of Fluid Mechanics, 1(1) :1-10, 2010.

[14] F. Hecht, O. Pironneau, A. Le Hyaric, and K. Ohtsuka. Freefem++ Manual, 2005.

[15] P. G. Doyle and J. L. Snell. Random walks and electric networks. Mathematical Association of America Washington, DC, 1984.

[16] A. Sheilds. Anwendungder aehnlichkei tsmechanik und der turbulenzforschung auf die geschiebebewegung. Mitteilungen der Preuss. Versuchsanst fur Wasserbau and Schiffbau, Berlin, 1936.

[17] V. A. Vanoni and W. M. Keck. Measurements of critical shear stress for entraining fine sediments in a boundary layer. California Institute of Technology, 1964.

[18] E. W. Lane. Design of stable channels. Transactions of the American Society of Civil Engineers, 120 :1234-1260, 1955.

[19] F. M. Henderson. Stability of alluvial channels. J. Hydraulics Div., ASCE, 87 :109-138, 1961.

[20] O. Devauchelle, A. P. Petroff, A. E. Lobkovsky, and D. H. Rothman. Longitudinal profile of channels cut by springs. Journal of Fluid Mechanics, 1(-1) :1-11, 2011.

[21] D. R. Montgomery. Predicting landscapescale erosion rates using digital elevation models. Comptes Rendus Geosciences, 335(16) :1121-1130, 2003.

[22] G. Lacey. Stable channels in alluvium. Institution of Civil Engineers, 1929.

[23] W. E. H. Culling. Analytic theory of erosion. J. Geol., 68 :336-344, 1960. 
[24] N. W. Bass. The geology of cowley county, kansas : Kansas geol. Survey Bull, 12 :1203, 1929.

[25] K. O. Emery. Asymmetric valleys of san diego county, california : Southern calif. acad. Sci. Bull, 46(pt 2) :61-71, 1947.

[26] B. N. Burnett, G. A. Meyer, and L. D. McFadden. Aspect-related microclimatic influences on slope forms and processes, northeastern arizona. Journal of Geophysical Research, 113(F3) :F03002, 2008.

[27] E. Istanbulluoglu, O. Yetemen, E. R. Vivoni, H. A. Gutiérrez-Jurado, and R. L. Bras. Eco-geomorphic implications of hillslope aspect : inferences from analysis of landscape morphology in central new mexico. Geophysical Research Letters, 35(14) :L14403, 2008.

[28] C. Kwit, M. W. Schwartz, W. J. Platt, and J. P. Geaghan. The distribution of tree species in steepheads of the apalachicola river bluffs, florida. Journal of the Torrey Botanical Society, 125(4) :309-318, 1998.

[29] I. Reda and A. Andreas. Solar position algorithm for solar radiation applications. Solar energy, 76(5) :577-589, 2004.

[30] A. E. Lobkovsky, B. E. Smith, A. Kudrolli, D. C. Mohrig, and D. H. Rothman. Erosive dynamics of channels incised by subsurface water flow. J. Geophys. Res, 112, 2007. 